\title{
Smart Grid Functionalities Evaluation
}

\author{
Laura Giménez de Urtasun, Samuel Borroy Vicente, Noemí Galán Hernández \\ CIRCE Foundation, Zaragoza, Spain \\ Email: lauragdu@fcirce.es, sborroy@fcirce.es, ngalan@fcirce.es
}

Received 11 May 2016; accepted 10 June 2016; published 13 June 2016

Copyright (C) 2016 by authors and Scientific Research Publishing Inc.

This work is licensed under the Creative Commons Attribution International License (CC BY).

http://creativecommons.org/licenses/by/4.0/

(c) (i) Open Access

\begin{abstract}
In the last years, with the advent of Smart Grids, many research and demonstration projects have seen the light in order to involve electric system in the implementation of advances in information and communication technologies, in order to improve network efficiency, reliability, security and quality of service. Before new implementations are performed, previous results have to be studied, and taken into account. In this line, this work presents the methodology, results and conclusions of the evaluation of the Smart Grid functionalities developed by 5 different DSOs during DISCERN project in order to select the optimal, cost-effective and most replicable solutions for the strategic development of the intelligence at medium voltage (MV) and low voltage (LV) networks.
\end{abstract}

\section{Keywords}

\section{Smart Grid, Power System Reliability, ASIDI, KPIs, Simulation}

\section{Introduction}

Distribution System Operators (DSOs) current challenge [1] is to adapt their network operations and business to newly developed technologies and solutions for medium and low voltage grids [2]. These advances are seen as a possible solution to current concerns like demand growth and increase of the use of distributed generators [3], at the same time that enable the achievement European commitments for 2020 [4], which are: reduction of consumption of primary energy, increase of the amount of renewable energies and reduction of the CO2 emissions. Therefore many demonstration projects on Smart Grids have emerged boosted by the own DSOs willing to try their new implementations on information and communication technologies in a controlled area and to see how much their objectives on network efficiency, reliability, security and quality of service could be fulfilled, [5].

Demonstration projects entail a considerable amount of investment and effort, and therefore it is reasonable that achievements and conclusions on a demonstration project result of high interest to other DSOs. Although it is important to keep in mind that each grid has its own characteristics and using a particular solution on a different location, what is called replicability, it is not straightforward. This is the reason why the collaborative 
projects appear in many scales. At national scale projects like PRICE or RedActiva can be found in Spain, and at European level can be found projects like DISCERN, Grid4EUor BestPaths, among many others.

Apart from contributing with different demonstration sites and gathering together the results from the exploitation of the demonstration sites, what all this projects have in common is that they need a methodology for the evaluation of the results technically and economically, and for the study of replicability and scalability of the solutions, understanding the concept of replicability as the possibility to translate a development from one specific location in a grid to a completely different one, and the scalability as the possibility to expand a development in a specific point of a grid to a wider area.

An important tool for the evaluation of Smart Grid functionalities is the definition of the objectives that any new implementation seeks, and how these objectives will be measured through Key Performance Indicators (KPIs) [6] and [7]. At the electric field, the European Electricity Grid Initiative (EEGI) agency defined a set of standardized KPIs that covered through three different KPI levels the way to evaluate any new deployment from the point of view of the technical achievements to their relationship with the main objectives to meet [8].

Simulations play an important role in these projects as they allow evaluating the studied technologies in grids that are not those at which the real implementation was deployed initially. Simulations allow studying either the replicability of a solution in another existing or future grid, or the scalability from a laboratory or demonstration grid implementation to large scale implementations. Although assumptions are required in order to allow a reasonable modelling, it is desirable to compare simulation results with those coming from the demonstration site, as it allows validating the characteristic of the novel technology or functionality that are being modelled and simulated. Furthermore, simulations evaluate the performance of the solution with different deployment levels, and check its behavior when exposed to situations that are not easy to reproduce in a controlled way at a laboratory or a real demonstration site.

The difference in investment is substantial when talking about the evaluation of the behavior of new implementations at a real demonstration site and simulating them, even more new technologies have been already tested in real sites when there exist projects, and the uncertainty comes from the decision on the deployment level to set in order to achieve the established goals, or the testing of the new technologies under different circumstances.

Under this framework, this paper presents the methodology followed at DISCERN project to evaluate the Smart Grid functionalities that different DSOs have already tested on their own demonstration sites in order to discern and select the optimal, cost-effective and most replicable solution for the distributed intelligence on medium voltage (MV) and low voltage (LV) networks. The paper is structured as follows: After this introduction, the tested functionalities are presented in Section 2. Section 3 presents the methods and concepts applied at the simulation task of the project. Most significant results of the simulation task are detailed in Section 4. Section 5 provides an explanation on the exploitable foreground and section 6 collects the conclusions.

\section{Smart Grid Functionalities Tested by Simulation}

Each company may have its own strategic objectives and therefore may have interest in developing some functionalities among the ones developed at the demonstration sites, therefore, when gathering the information from demonstration projects it is important to select those functionalities of interest for each company in the consortium. In the specific context of DISCERN project some of the power system functionalities selected are:

- Enhanced monitoring and control of MV/LV network.

- Calculation and separation of technical and non-technical losses.

- Aggregating flexible loads for power flow control and congestion management.

- Use of flexible storage for power flow control ancillary services.

Following a description and particular application of these functionalities that was tested by simulations is presented. Other applications of the functionalities are possible, but the ones presented here are those that were applied by DISCERN partners.

\subsection{Enhanced Monitoring and Control of MV/LV Network}

The objective of simulations performed with this functionality is to investigate different levels of supervision and automation in order to analyze and enhance the continuity of service. The impact on outage detection and isolation and therefore the improvement of the quality of service is assessed. 
Different procedures and technologies have been analyzed:

1) "Basic" situation

At which the only information that the Control Centre (CC) receives is the trip of the feeder circuit breaker and there is no tele control (TC);

2) "Actual” situation

Which represents the reference related to the Business as Usual (BaU) use case. At this situation a low level of tele control is normally found in the lines of the demonstration projects, although each network has a different initial automation level;

3) "Fault passage indicator" (FPI) technology

Where this technology is installed at several secondary substations along the line in order to send information that would help to locate the fault; and

4) "Fault locator at Primary Substation" (FLT) technology

This technology is installed at the primary substation of the line, in order to calculate the location of the fault.

Furthermore, three different automation levels are considered to be developed at the simulations: 5\%, 10\% and $20 \%$ of the secondary substations (SS). To have an automated SS means to have tele control and fault location technology devices installed on them (if necessary, as for the FLT, the technology is installed at primary substation and at SS only automation is needed), and it is always related to the Research and Development (R\&D) use cases.

\subsection{Calculation and Separation of Technical and Non-Technical Losses}

The objective of the simulations at this functionality is to check the influence that different levels of supervision at LV level could have on the calculation of technical and non-technical losses. Supervision is normally held by smart meters, SM, installed in first instance at customer premises, although for further deployments it is considered that they are installed at intermediate points of the network. The analyses should show if increasing the number of SM, installing them not only at customers or generators premises, allows a more accurate calculation of technical and non-technical losses that could justify the increase of supervision at the LV network.

Following are presented the different considerations taken into account in order to set the simulation scenarios:

1) Supervision level

Three scenarios according to the supervision level, that allows to set three calculation areas:

o Circuit area supervision: The first situation would be the actual or BaU situation at DSO. The calculation of technical and non-technical losses is performed considering all the incoming energy at the circuit and all the consumption and generation registered by SM at customers and generators premises.

o Feeder area supervision: Additionally to the SM used at customers and generators premises, more SM are installed at feeder header. In this way the calculation area is reduced at feeder area and calculation and losses location accuracy improves with respect to circuit area calculation.

o Smaller area supervision: Further SM are installed additionally to the Feeder area supervision deployment, allowing a smaller calculation area.

2) Non-declared loads level and concentration

Non-declared loads level is adjusted to $5 \%$ of total energy losses. Although this value is not real, it is set as fixed in order to help the estimations on the accuracy of the calculation.

Additionally two scenarios considering the concentration level of non-technical losses are set: One scenario considers concentrated non-technical losses; whereas the other scenario considers uniformly distributed nontechnical losses over the network.

3) Load and generation characteristics

General daily profiles of load and generation are used.

4) Phase load unbalances

The effects of phase load unbalances on power losses are studied as well. When loads are unbalanced among phases, technical losses are higher than in the case of perfectly balanced loads among phases.

At Figure 1, schema of the three supervision levels, and the calculation area that they allow is shown.

The combination of the power system simulation scenarios for this functionality provides the complete Table 1 of scenarios simulated. 
Circuit area supervision

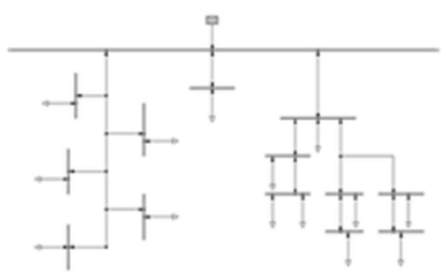

Feeder area supervision

Smaller area supervision
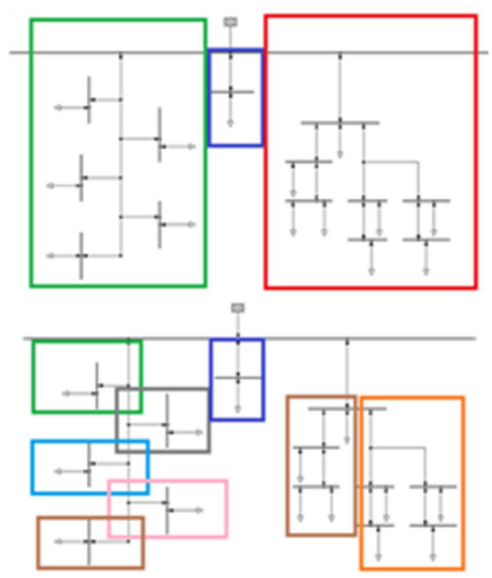

Figure 1. Supervision levels for losses calculation at benchmark network.

Table 1. Power system simulation scenarios at this functionality.

\begin{tabular}{|c|c|c|c|c|c|c|c|c|c|c|c|}
\hline & & \multicolumn{10}{|c|}{ Scenarios } \\
\hline & & 1 & 2 & 3 & 4 & 5 & 6 & 7 & 8 & 9 & 10 \\
\hline \multirow{3}{*}{$\begin{array}{c}\text { Technology } \\
\text { deployment level }\end{array}$} & Circuit area supervision & $\mathrm{X}$ & & & & & $\mathrm{X}$ & & & & \\
\hline & Feeder area supervision & & $\mathrm{X}$ & $\mathrm{X}$ & & & & $\mathrm{X}$ & $\mathrm{X}$ & & \\
\hline & Smaller area supervision & & & & $\mathrm{X}$ & $\mathrm{X}$ & & & & $\mathrm{X}$ & $\mathrm{X}$ \\
\hline \multirow{2}{*}{$\begin{array}{l}\text { Non-technical losses } \\
\text { concentration }\end{array}$} & Uniformly & & & & & & $\mathrm{X}$ & $\mathrm{X}$ & $\mathrm{X}$ & $\mathrm{X}$ & $\mathrm{X}$ \\
\hline & Concentrated & $\mathrm{X}$ & $\mathrm{X}$ & $\mathrm{X}$ & $\mathrm{X}$ & $\mathrm{X}$ & & & & & \\
\hline \multirow{2}{*}{ Load phase balancing } & Unbalanced & $\mathrm{X}$ & & $\mathrm{X}$ & & $\mathrm{X}$ & & $\mathrm{X}$ & & $\mathrm{X}$ & \\
\hline & Balanced & & $\mathrm{X}$ & & $\mathrm{X}$ & & $\mathrm{X}$ & & $\mathrm{X}$ & & $\mathrm{X}$ \\
\hline
\end{tabular}

First and sixth scenarios correspond to the BaU use case considering that non-technical losses are concentrated and uniformly distributed respectively. These two scenarios consider a unique energy balance area ("Circuit area supervision”) and loads or consumers are unbalanced. They are set as reference cases.

\subsection{Aggregating Flexible Loads for Power Flow Control and Congestion Management}

This functionality simulations objective is to provide results to DSOs that could allow them the investigation of new business related to flexible loads (like EV and water heaters). This functionality was not applied at any previous demonstration site, although interest of all the DSOs involved in DISCERN was clear and therefore, it was decided to simulate it.

In order to obtain the relative influence of load flexibility to demand curve flattening and energy efficiency, different rates of load flexibility penetration are set up. It has been considered that $0 \%, 5 \%, 10 \%$ or $25 \%$ of consumption power of the system were flexible loads that are allocated uniformly. The diverse penetration rates constitute several simulation scenarios, which are presented in Table 2. 
Table 2. Simulation scenarios at this functionality.

\begin{tabular}{cccccc}
\hline & & \multicolumn{3}{c}{ Scenarios } \\
\cline { 3 - 5 } & & 1 & 2 & 3 & 4 \\
\hline \multirow{2}{*}{ Load flexibility penetration } & $0 \%$ & $\mathrm{X}$ & & & \\
& $5 \%$ & & $\mathrm{X}$ & $\mathrm{X}$ \\
\hline
\end{tabular}

\subsection{Use of Flexible Storage for Power Flow Control and Ancillary Services}

This functionality simulations objective is to provide results to DSOs that could allow them the investigation of new business related to flexible storage. Due to the actual regulations, storage is not regulated at DSOs countries, therefore although this functionality was not applied at any previous demonstration site, interest of all the DSOs involved in DISCERN was clear and it was decided to simulate it as well, as it happened with the previous functionality for flexible loads.

In order to obtain the relative influence of storage flexibility to demand curve flattening and energy efficiency, and in the exact way as done in the load flexibility study, different rates of storage flexibility penetration are set up. It has been considered that $0 \%, 10 \%$ or $40 \%$ of consumption power of the system was flexible storage uniformly distributed. The diverse penetration rates constitute several simulation scenarios, which are presented in Table 3.

\section{Simulation Method and Concepts}

Prior to explaining the simulation methodology, some essential concepts must be introduced, such as:

- Benchmark networks.

- 3L Concept (Leading-Learning-Listening).

- Communications.

- Fortuitous occurrence of faults.

- Actuation times and communication variability.

\subsection{Benchmark Networks}

General studies concerning distribution systems can only be performed on some exemplary networks. The proper selection of these networks is crucial for the validity and consistency of the results of the study, which shows the need for benchmark networks representing the important influencing parameters. Furthermore, due to confidentiality issues and the difficulties that some DSOs may have to deliver the necessary network data or solution details, benchmark networks represent a clear solution.

Under this framework, two benchmark distribution networks (one for LV and another for MV level) have been selected. It has been agreed to use this couple of networks for distribution systems obtained from the International Council on Large Electric Systems, CIGRE [9]-[11]. The selection of these benchmark models ensures that all other network characteristics will be similar to most of the European networks.

1) MV benchmark distribution network

Figure 2 presents the one-line diagram of this benchmark network.

2) LV benchmark distribution network

The one-line diagram of the LV benchmark distribution network to be used in DISCERN is presented in Figure 3. This network model is composed of three LV feeders: one for residential customers (left side of the figure), one for an industrial load (in the middle), and another feeder for a commercial load (right side of the figure).

\subsection{L Concept}

In the early stages of DISCERN project [12], "3L" concept, Leading-Learning-Listening, was defined. The main idea behind this view is summarized in Figure 4, through which each DSO takes on one of the three available 


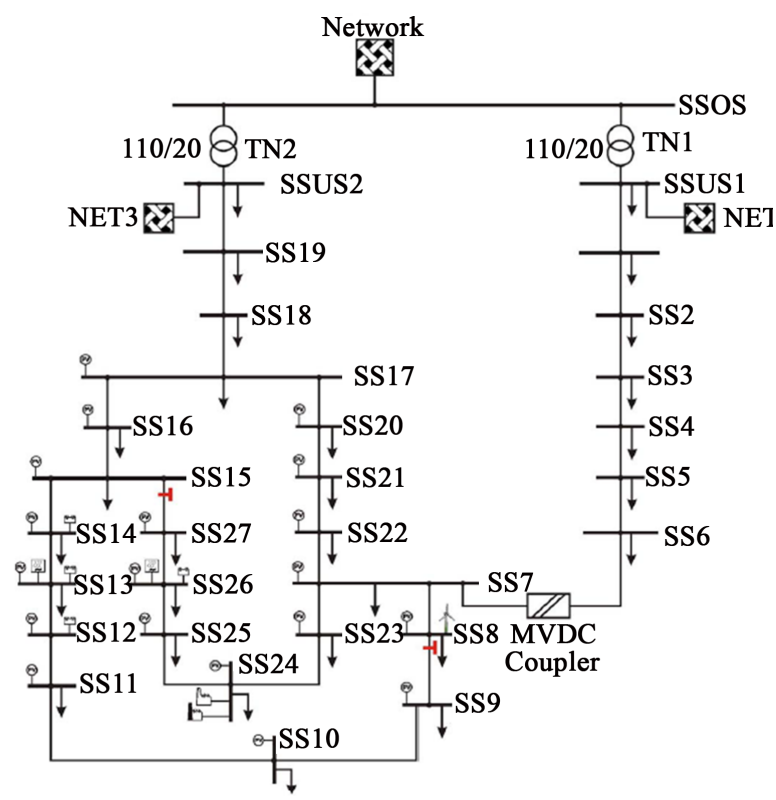

Figure 2. One-line diagram of the MV benchmark distribution network [10].

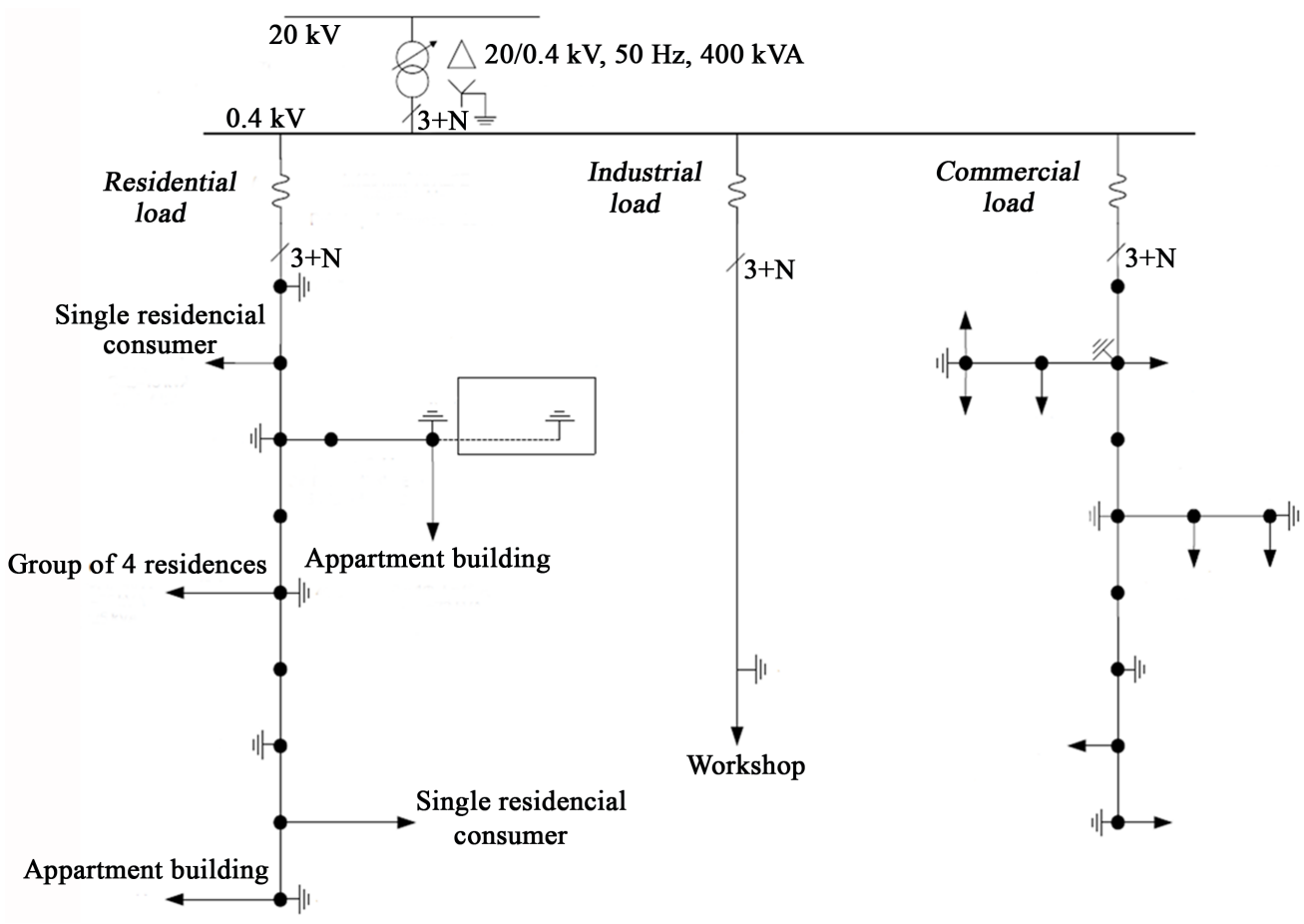

Figure 3. One-line diagram of the LV benchmark distribution network [11].

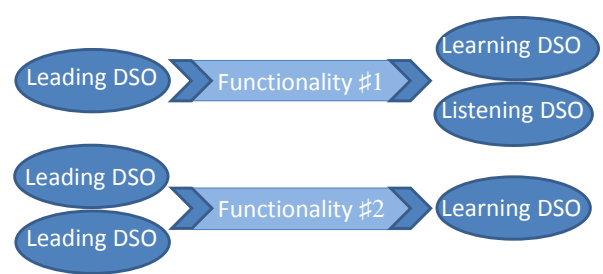

Figure 4. 3L Concept of discern: leader, learner, listener associated with functionalities. 
Table 3. Simulation scenarios at this functionality.

\begin{tabular}{ccccc}
\hline & & \multicolumn{2}{c}{ Scenarios } \\
\cline { 3 - 4 } & & 1 & 2 & \\
Storage flexibility penetration & $0 \%$ & $\mathrm{X}$ & $\mathrm{X}$ & \\
& $10 \%$ & & $\mathrm{X}$ \\
\hline
\end{tabular}

roles (3L concept), Leader, Learner or Listener, in relation to a specific functionality. Firstly, leading DSO projects are characterized by the fact that the respective DSO had already developed and implemented a solution for the specific Smart Grid functionality. Secondly, learning DSOs were interested in the implementation of the technical solution for a functionality. In the third place, listening DSOs followed functionalities on which they had not made any considerations regarding the concrete implementation but were keen to take into consideration the results from the project.

\subsection{Communications}

Communications are an important part on DISCERN solutions as the previous ("traditional") operation procedures of the grid did not rely so much in them. Therefore, special attention is made on the study of the effect of communications. Two possible effects of an incorrect operation of communications are considered, taking into account the results for communications at [13]:

1) Delays

On one hand it is studied the effect of the delays of communications when sending orders or information between devices and CC, what is also called latency. This effect is considered applying the actuation times at each step of the process that was completely disaggregated.

2) Loss of communications

On the other hand, it was as well studied the effect of a partial or total loss of the communications during the process of fault awareness, location and isolation. It has been considered that in the case of communications failure, the described "automated" procedures, the ones that depend on communications, with FPI and FLT devices, would be stopped, and the "basic" procedure (faulted line clearing procedure with no fault location technology at all) would be initiated as it does not depend on communications.

In the following Figure 5, a schema example on how one communication failure effect is considered on an "automated" procedure.

It is important to state that the more dependency on communications, the bigger the effect that their failures have on the procedure, and on the faulted line restoration, and therefore it is important to take into account all the communications of the procedure.

\subsection{Fortuitous Occurrence of Faults}

At certain simulations it is important to take into account the fortuitous occurrence of faults. This feature makes it difficult to analyze real measurements of KPIs like ASIDI or SAIDI in small areas and in a limited period of time as their value would vary a lot from a period with lots of storms or hazards, to a period when weather conditions were not so extreme or there were no hazards at all. Therefore it is difficult to evaluate any faulted line clearing procedure only through the on-site measurements of a demo-site since the results have a great dependency with random factors. This fortuitous effect is diluted when talking of big areas, like the whole grid of a distribution company, due to the compensation that is partly produced when considering many lines and a wide area with many different weather conditions on it [14] and [15].

Another important aspect to take into account is that the total time for fault location, isolation and service restoration (when the service is restored to the last affected customer after the incident) not only depends on the technology used, but as well on the place of the line where the fault is located. If a fault is located near to the primary substation or in a place where the number of customers or consumed power is low, its effects on the ASIDI and SAIDI KPIs, would be much lower than in any other location. 


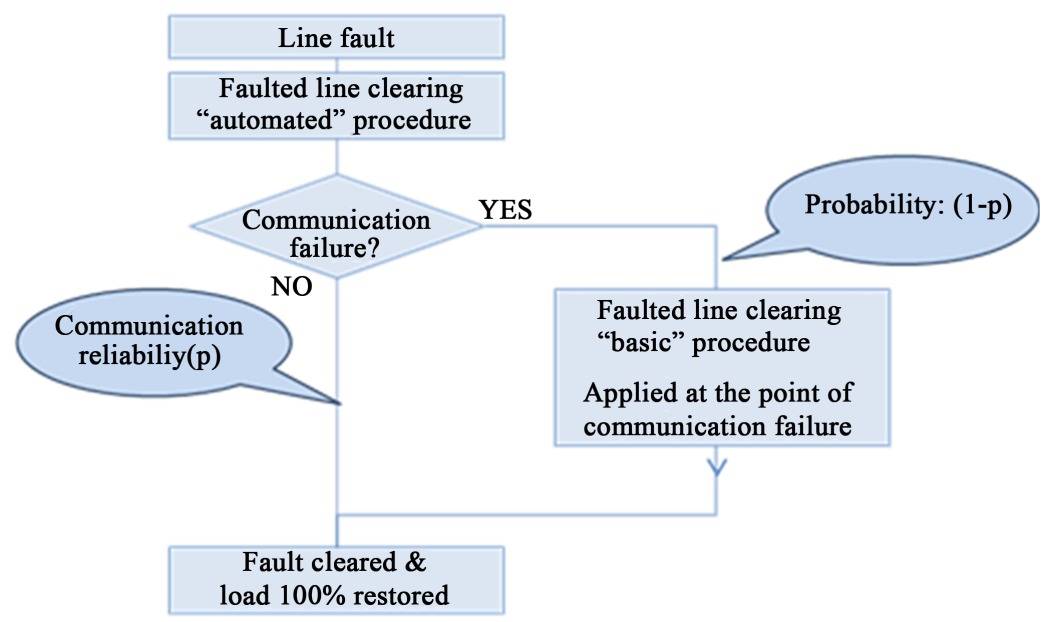

Figure 5. “Automated” Faulted line clearing procedure considering the effect of a communication failure.

In order to consider all these features and to remove the fortuitous effect of faults occurrence, the simulation process has been designed so that a fault with impact on the automation is applied at each stretch of line of the modelled networks. Considering each of the procedures and actuation times that were described in the previous sections, the time required for fault awareness, location and isolation is obtained. Furthermore thanks to the grids and procedures models, the way in which the service is restored at the different customers, as the clearing procedure progress, can be taken into account in order to calculate the KPIs.

At Figure 6 it is presented the analysis of the MV benchmark network, considering the scenario of an automation level of $20 \%$. Automated SS are pointed out at the figure with red rhombuses. For each of the faults, a different value of the KPI SAIDI is obtained.

Afterwards, an average value for each of those KPIs is obtained, considering that the fault occurrence probability is the same at each point of the line, and considering how the load is distributed along it.

Once obtained those KPIs values, they need to be processed to be unified to a normal number of faults during the considered period. This is done obtaining the value of the "not affected power" that corresponds to the size of the grid that our model should have in order to allocate all those considered faults with the same fault probability that a real DSO network would have.

\subsection{Actuation Times and Communication Variability}

Actuation times and communication reliability values have been obtain from approaches obtained at DSOs. This estimation cannot be improved easily and therefore the effect that the variation in them could have on the assessment of the KPIs should be characterized. In this line, a difference of $5 \%$ at the actuation times and at the communication reliability used values has been applied and it has been seen that the dependency of the results on these values variations is minimum.

\subsection{Simulation Methodology}

With this framework in mind, the simulation methodology specifically designed for DISCERN is now presented. For each of the functionalities, the following procedure will be following:

1) Verification and validation

Simulation models are approximate reproductions of real-world systems, but they never exactly emulate them. Due to this fact, simulation models must be verified and validated according to the real data measured in the real-world. For this reason, the first phase of the simulation methodology includes the validation of the simulation model with the leader DSO.

2) Simulations at Learner DSO network

Once the created simulation model is validated in the previous stage, all the simulation scenarios defined for each functionality are carried out at the learner DSO network. This approach provides a valuable wide range of 


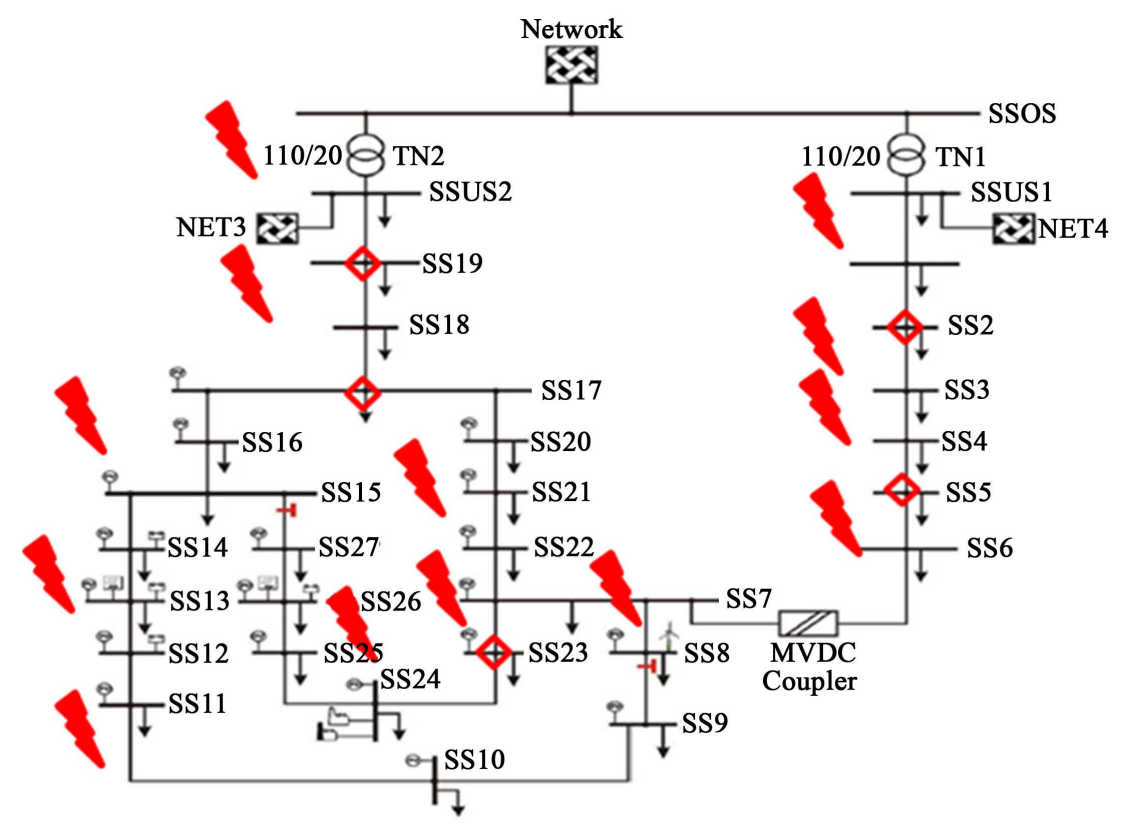

Figure 6. MV benchmark network with $20 \%$ of automation level, showing the faults applied at the line stretches where the fault clearing process behaviour is different [16].

results to learner DSOs because they obtain not only the real results from leader DSOs but also the simulated results generated from the model of their networks.

3) Simulations at benchmark network

In a similar way as it was defined at the second phase, once the created simulation model is validated at leader network, all the simulation scenarios defined for each functionality will be carried out at the benchmark network.

\section{Significant Results}

\subsection{Enhanced Monitoring and Control of MV/LV Network}

The results obtained for the simulations at this functionality are presented through the values of SAIDI (security of supply). This KPI considers not only the times, but as well the curtailed load for each step of the restauration procedure.

The values for SAIDI at the three automation levels: $5 \%, 10 \%$ and $20 \%$ of the SS are given for the benchmark network in the following Table 4.

In the following graph (Figure 7) the improvement in SAIDI, of each of the "automated" scenarios (R \& D), can be seen in relation to the actual scenario (BaU).

From simulation results it is concluded that all the implementations improve the actual situation, shown with a green line in the previous Figure 7.

Although it is considered that CBA analysis is needed in order to validate that the improvements achieved could justify the investment on each increased automation deployment degree.

\subsection{Calculation and Separation of Technical and Non-Technical Losses}

The results obtained for the simulations at this functionality are presented through the values of three KPIs defined at [17]:

Amount of technical losses identified (LV): Technical losses $\left(\mathrm{Lo}_{\text {tech }}\right)$ are calculated for the actual network situation and presented as a rate of the total energy delivered and consumed by end customers ( $\mathrm{E}_{\text {Customers }}$ ).

$$
\mathrm{E}_{\text {tech loss }}(\%)=\frac{\mathrm{Lo}_{\text {tech }}}{\mathrm{E}_{\text {Customers }}} \times 100
$$




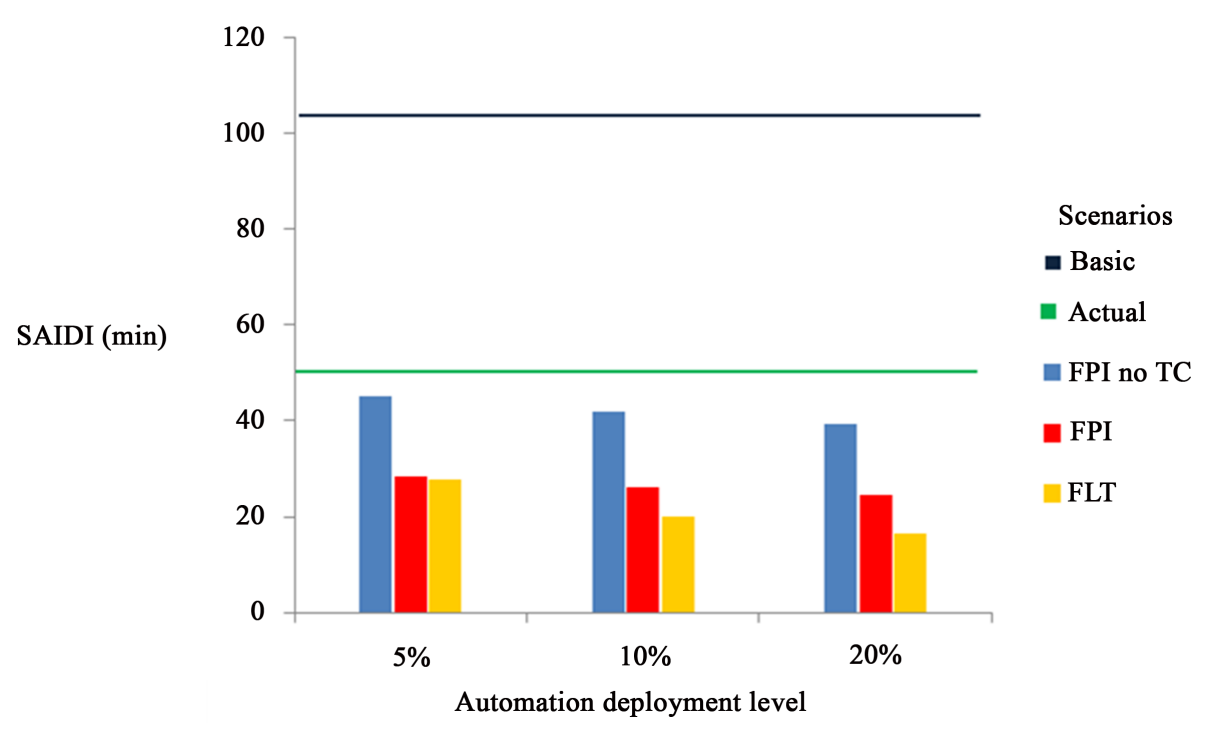

Figure 7. Simulation SAIDI values (minutes) at functionality performed at the Benchmark network for the different scenarios.

Table 4. Simulation results for this functionality.

\begin{tabular}{cccc}
\hline Fault location technology & Automation deployment level (\%) & Names & SAIDI (min) \\
\hline None & - & Basic & 90.46 \\
Actual & - & Actual & 66.11 \\
& 5 & $5 \%$ FPI no TC & 64.61 \\
Fault passage indicator without \\
tele control (FPI no TC) & 10 & 10\% FPI no TC & 57.59 \\
& 20 & $20 \%$ FPI no TC & 54.52 \\
Fault passage indicator (FPI) & 5 & $5 \%$ FPI & 34.05 \\
& 10 & $10 \%$ FPI & 37.68 \\
Fault location technology at primary & 20 & $20 \%$ FPI & 53.18 \\
substation (FLT) & 5 & 5\% FLT & 53.53 \\
& 10 & 10\% FLT & 36.73 \\
\hline
\end{tabular}

Potential for reduction in technical losses balanced network (LV): After applying the balancing at the load phases, the difference between technical losses in actual scenario (unbalanced) ( $\mathrm{Lo}_{\text {tech unbalanced }}$ ) and technical losses in load phase balanced scenario ( $\mathrm{Lo}_{\text {tech balanced }}$ ) is calculated and presented as a rate of the technical losses in actual scenario.

$$
\Delta \mathrm{Lo}_{\text {tech balance }}(\%)=\frac{\mathrm{Lo}_{\text {tech unbalanced }}-\mathrm{Lo}_{\text {tech balanced }}}{\mathrm{Lo}_{\text {tech unbalanced }}} \times 100
$$

Amount of non-technical losses identified (LV): Non-technical losses ( $\mathrm{Lo}_{\text {non-tech losses }}$ ) are calculated for the actual network situation and presented as a rate of the total energy delivered and consumed by end customers.

$$
\mathrm{E}_{\text {non-tech loss }}(\%)=\frac{\mathrm{Lo}_{\text {non-tech }}}{\mathrm{E}_{\text {Customers }}} \times 100
$$


The values for these 3 KPIs at the different scenarios are given for the benchmark network in the following Table 5 and Table 6.

From simulation results it is concluded that:

o The amount of technical losses identified on the balanced cases is lower than on the unbalanced cases;

o As calculation zones are reduced the identified losses error is reduced as well considerably;

o The difference between considering the non-technical losses in a unique point (concentrated) or along the grid (distributed) is minimum.

\subsection{Aggregating Flexible Loads for Power Flow Control and Congestion Management}

In Figure 8, the action range of load flexibility is remarked with the help of a blue background and two discontinuous lines.

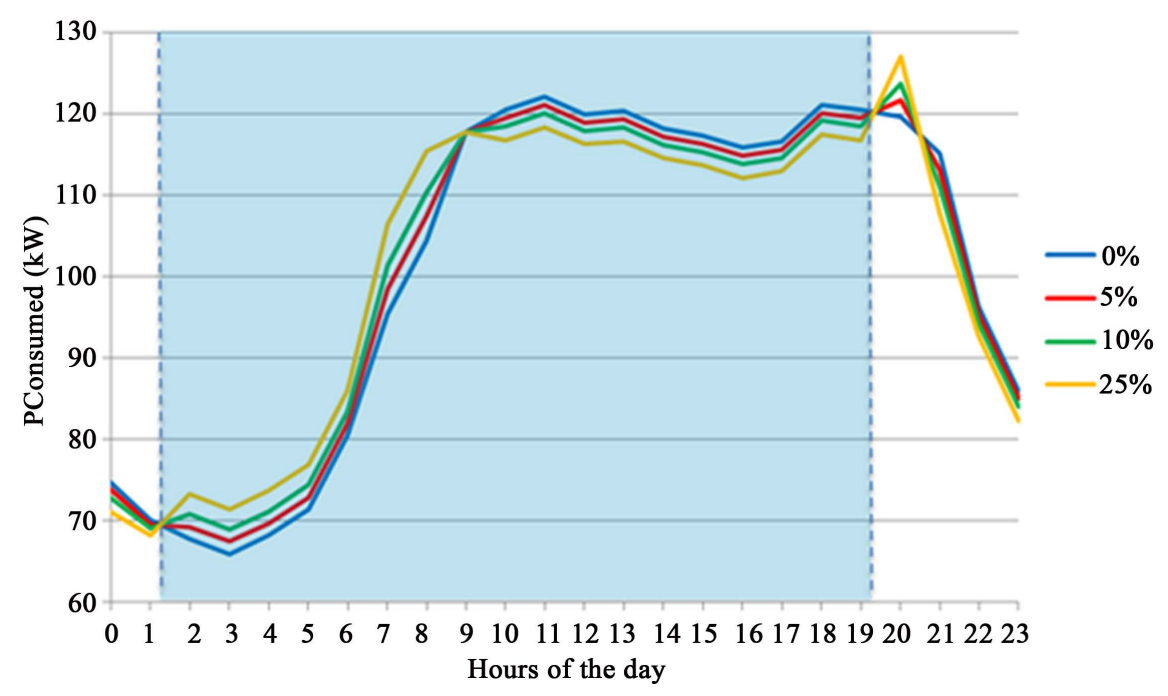

Figure 8. Total system consumption in the four different scenarios.

Table 5. Simulation KPI values at the benchmark network for concentrated non-technical losses.

\begin{tabular}{|c|c|c|c|}
\hline Scenario & $\begin{array}{l}\text { Amount of technical } \\
\text { losses identified }\end{array}$ & $\begin{array}{l}\text { Potential for reduction in } \\
\text { technical losses balanced network }\end{array}$ & $\begin{array}{l}\text { Amount of non-technical } \\
\text { losses identified }\end{array}$ \\
\hline Scen. 1-BaU, conc, unbalan. & 1.82 & Reference case & 2.27 \\
\hline Scen. 2-Feeder, conc, balan. & 0.73 & 59.86 & 3.22 \\
\hline Scen. 3-Feeder, conc, unbalan. & 1.75 & - & 2.33 \\
\hline Scen. 4-Small, conc, balan. & 0.51 & 72.02 & 3.66 \\
\hline Scen. 5-Small, conc, unbalan. & 1.33 & - & 2.55 \\
\hline
\end{tabular}

Table 6. Simulation KPI values at the benchmark network for uniformly distributed non-technical losses.

\begin{tabular}{lccc}
\hline \multicolumn{1}{c}{ Scenario } & $\begin{array}{c}\text { Amount of technical } \\
\text { losses identified }\end{array}$ & $\begin{array}{c}\text { Potential for reduction in } \\
\text { technical losses balanced network }\end{array}$ & $\begin{array}{c}\text { Amount of non-technical } \\
\text { losses identified }\end{array}$ \\
\hline Scen. 6-BaU, unif, unbalan. & 1.76 & Reference case & 1.27 \\
Scen. 7-Feeder, unif, balan. & 0.70 & 62.08 & 3.25 \\
Scen. 8-Feeder, unif, unbalan. & 1.80 & - & 2.29 \\
Scen. 9-Small, unif, balan. & 0.49 & 73.07 & 3.39 \\
Scen. 10-Small, unif, unbalan. & 1.29 & - & 2.52 \\
\hline
\end{tabular}


As it can be observed, the more load flexibility is introduced, the more flattened is the demand curve at the restricted hours. Energy consumption remains the same, due to the load shifting action on the domestic consumers of the system. It is noticeable how the consumption from 9 a.m. to 7 p.m. is shifted to valley hours. During the valley between 1 a.m. to 8 a.m. the increase of demand because of the influence of flexible domestic clients presents the desired effect. Whereas as a counterpoint, the consumption peak at 9 p.m. is dramatically increased. In order to avoid this undesired effect, valley hour should be delayed, or further demand side management actions, like dynamic time-of-use tariffs, should be implemented.

As a proof of load flexibility as an energy efficiency solution for the customer, the OMIE hourly intraday market energy price is used in order to determine the cost of the total system's consumption. In this case, the hourly energy price of the 1st of July in 2014 is considered, which is a random day matching the same period of time of the load consumption characteristic conferred to the several load types used in the simulations.

The financial results obtained for the total system's consumption in all cases are presented in Table 7. The outcome reveals certain daily money saving for the consumer, which it is not as relevant as the demand curve flattening results presented. However, it means that load flexibility can help clients in matters of getting them involved in demand side management activities, because they mean savings in their energy billings.

Although daily results may not seem relevant, being for the total system, making a simple approximation of what it could be monthly obtained becomes more appealing from the client point of view. In this case, if the eight weekend days of July are not taken into account, it is possible to guess the estimated money saving for the flexible clients of the considered system in their monthly billing, directly multiplying the daily savings by the rest week days of the month (23). According to this approach, the outgoing is also presented in Table 7.

In view of the gathered results, load flexibility is a clear solution in energy efficiency not only for electrical companies thanks to the demand curve flattening presented in Figure 8; but also for their clients, because it means an important monthly savings in its energy billings. Then, load flexibility can be considered as an important incentive for both parts when undertaking demand side management activities.

\subsection{Use of Flexible Storage for Power Flow Control Ancillary Services}

In Figure 9, the action range of storage flexibility is remarked with the help of a blue background and two discontinuous lines.

Regarding this functionality, where the action range of the action carried was limited to a certain range, the flexible storage introduced by the EV2G of the domestic clients, allows influencing the demand curve over the whole day.

Besides, as it can be seen, the more storage flexibility is introduced, the more flattened is the demand curve with the same energy consumption, due to the load shifting action carried out on the domestic consumers. It is noticeable how consumption in peak hours is shifted to valley hours, because of the influence of flexible domestic clients.

For testing if storage flexibility can be an energy efficiency solution for the customer, the OMIE hourly intraday market energy price is used in order to determine the cost of the total system's consumption. In this case, the hourly energy price of the 1st of July in 2014 is considered, which is a random day matching the same period of time of the load consumption characteristic conferred to the several load types used in the simulations.

The economic quantification of the results obtained in total consumption in all cases, are presented in Table 8. The outcome reveals certain daily money saving for the customer, even when introducing a $10 \%$ of flexible storage clients, can help DSOs in the process of involving their customers in demand side management activities, because they mean savings in their energy billings.

Table 7. Financial translation and daily and monthly billing savings obtained at the total system.

\begin{tabular}{cccc}
\hline Load flexibility level & Energy billing (€/day) & Daily savings ( $€ /$ day $)$ & Monthly savings $(€ /$ month) \\
\hline $0 \%$ & 115.85 & 0 & 0 \\
$5 \%$ & 115.72 & 0.13 & 6.99 \\
$10 \%$ & 115.58 & 0.27 & 11.27 \\
$25 \%$ & 115.36 & 0.49 & 0.21 \\
\hline
\end{tabular}




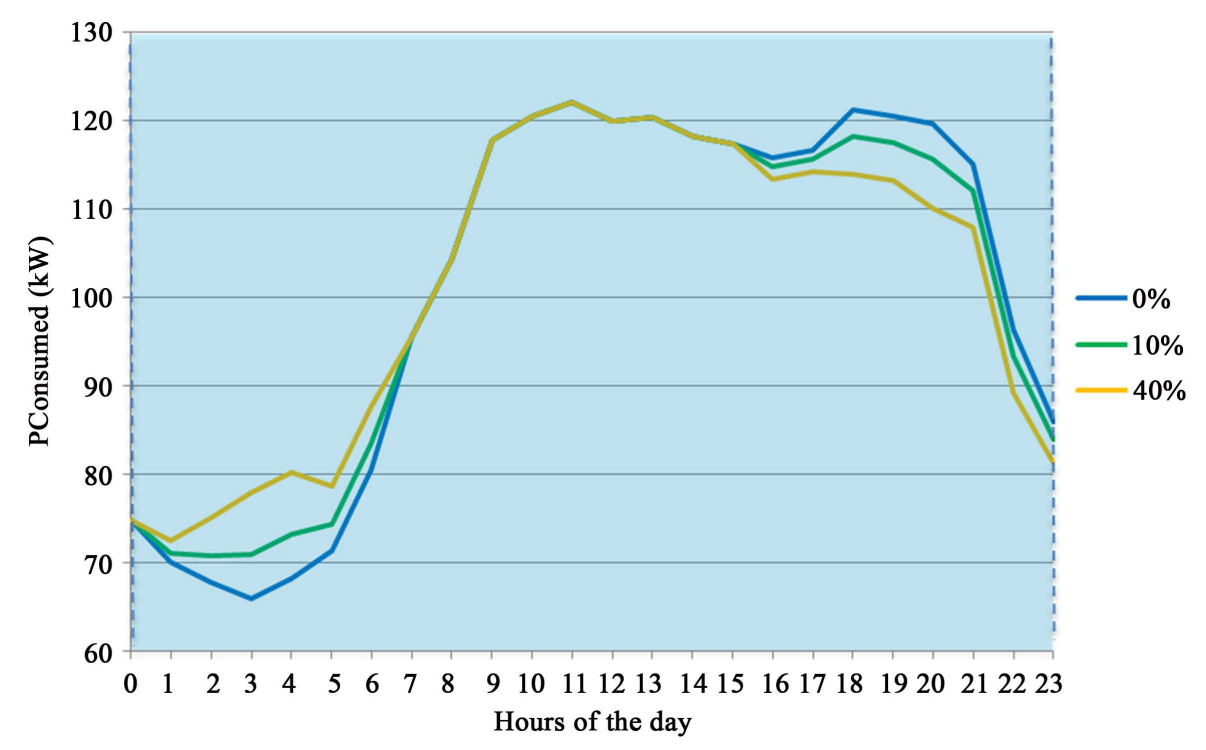

Figure 9. Total system consumption in the three different scenarios.

Table 8. Financial translation and daily and monthly billing savings obtained at the total system.

\begin{tabular}{cccc}
\hline Load flexibility level & Energy billing (€/day) & Daily savings $(€ /$ day $)$ & Monthly savings $(€ /$ month $)$ \\
\hline$\%$ & 115.85 & 0 & 0 \\
$5 \%$ & 115.72 & 0.13 & 6.99 \\
$10 \%$ & 115.58 & 0.27 & 6.21 \\
$25 \%$ & 115.36 & 0.49 & 11.27 \\
\hline
\end{tabular}

In order to translate daily results into a more relevant measure for energy billing, making a simple approximation of what it could be monthly obtained becomes more appealing from the client point of view.

In this case, if the eight weekend days of July are not taken into account, it is possible to guess the estimated money saving for the flexible clients of the considered system in their monthly billing, directly multiplying the daily savings by the rest week days of the month (23). According to this approach, the outgoing is also presented in Table 8.

In view of the gathered results, storage flexibility is a clear solution in energy efficiency not only for electrical companies seeking to obtain demand curve flattening, such as the one presented in Figure 9; but also for their customers, because it means an important monthly saving in the energy billing. Therefore, storage flexibility becomes an important incentive for both parts when planning demand side management activities.

\section{Exploitable Foreground}

One of the ideas of further exploitation is to develop a tool for the evaluation of new technology or control implementations on the electric grid based on the definition of objectives for the improvement on the energy quality and efficiency. Some of the most important characteristics of this tool would be that:

o Objectives and evaluation would be related through the use of KPIs;

o Grid data would be obtained from the CIM model;

o The tool would be able to provide or integrate most of the necessary simulation results based on the functionalities and technology description;

o That it would be necessary to choose for the optimal solution among the possible ones.

This tool would combine the DISCERN tools and methodologies with a view to developing a software platform that fully integrates all smart grid sites and relevant stakeholders, such as: planning and operation experts, ICT \& standards specialists, and hardware/software simulation labs. This repository could be expanded to in- 
clude the KPI framework and definitions of an agreed set of common KPIs to enable a Learner to benefit from the experiences of previous projects.

\section{Conclusions}

This paper has presented the complete methodology used at DISCERN project simulations in order to evaluate the new implementations and technologies proposed by DSOs for different functionalities of the grid.

The most significant learnings that could be used for similar projects are:

o KPIs objective is to evaluate and compare the different solutions for a specific functionality, although they cannot be use in order to compare the solutions at different demo sites.

o Through simulations undertaken on the same network model, different technical solutions for the same functionality can be assessed, providing valid and valuable KPI results for comparison purposes.

o In order to compare different technical solutions without the need to consider network specific factors, the definition and use of a benchmark network is a good and informative approach.

o Simulations have proved to be a suitable tool for analysis of the deployment of new solutions or deployment of increased numbers of devices, before any actual, physical implementation is undertaken at sites on a network.

o Through simulations, it is possible to calculate KPIs for those situations where real site measurements cannot be obtained, or when the optimum measurement period is too big compared to the test period.

o Based on this simulation work undertaken within DISCERN project the recommendations to different smart grid stakeholders are as follows:

o Simulations have proved to be a valuable tool for providing insight that guides more efficient investment on demonstration or real sites deployments. Therefore, as part of the design of any new deployment, it is recommended that DSOs undertake simulations before the physical implementation is planned and commenced. Further, all the relevant information should be gathered for calculation of KPIs in the BaU Case to allow subsequent comparison with KPIs calculated for the R\&D Case for simulation results or after implementation in the grid, allowing a robust comparison to be made and draw conclusions on the impacts and benefits of the new solution.

o The use of benchmark networks for both power grids and communication systems facilitates the useful and valid comparison of results of simulations. It is recommended that consultants and academic organizations to use this approach for projects which compare solutions for potential implementation on a range of networks, using a benchmark network that is representative of European DSO networks, such as those readily available from open sources.

\section{Acknowledgements}

The authors would like to express their appreciation to Iberdrola Distribución, RWE Deutschland Aktienfesellschaft, Southern Electric Power Distribution PLC, Unión Fenosa Distribución and Vattenfall Research and Development $A B$ for contributing with valuable comments under the PRICE-RED and DISCERN projects framework.

\section{References}

[1] Hidayatullah N.A., Stojcevski, B. and Kalam, A. (2011) Analysis of Distributed Generation Systems, Smart Grid Technologies and Future Motivators Influencing Change in the Electricity Sector. Smart Grid and Renewable Energy, 2, 216-229. http://file.scirp.org/pdf/SGRE20110300001_32428639.pdf

[2] Gaudó, M., González, R., Borroy, S., Giménez de Urtasun, L., Martín, S. and GarcíaGracia, M. (2014) Smart Grid Technologies Evaluation through KPIs. Proceedings CIRED Conference, Rome, 11-12 June 2014, 0398.

[3] Khalil, H.B. and Abas, N. (2014) Smart Grids: An Approach to Integrate the Renewable Energies and Efficiently Manage the Energy System of Pakistan. Proceedings International Conference on Computing, Communication and Networking Technologies, Heifei, 11-13 July 2014, 1-7. http://dx.doi.org/10.1109/iccont.2014.6963060

[4] EU Commission (2011) Europe 2020 Strategy. http://ec.europa.eu/europe2020/index es.htm

[5] Shafiullah, G.M., Oo, A.M.T., Ali, A.B.M.S. and Wolfs, P. (2013) Smart Grid for a Sustainable Future. Smart Grid and Renewable Energy, 4, 23-34. http://file.scirp.org/pdf/SGRE_2013022615342020.pdf 
[6] Ortmeyer, T.H., Reeves, J.A., Hou, D.Q. and McGrath, P. (2010) Evaluation of Sustained and Momentary Interruption Impacts in Reliability-Based Distribution System Design. IEEE Transactions on Power Delivery, 25, 3133-3138. http://ieeexplore.ieee.org/xpls/icp.jsp?arnumber=5565542 http://dx.doi.org/10.1109/TPWRD.2010.2052075

[7] Royal Decree 1048/2013 (2013) Metodología para el cálculo de la retribución de la actividad de distribución de energía eléctrica. Spanish Ministry of Industry, Energy and Tourism. https://www.boe.es/diario_boe/txt.php?id=BOE-A-2015-13782

[8] EEGI (2013) Research and Innovation Roadmap 2013-2022, http://www.gridplus.eu/Documents/20130228 EEGI\%20Roadmap\%202013-2022 to\%20print.pdf

[9] Rudion, K., Orths, A., Styczynski, Z.A. and Strunz, K. (2006) Design of Benchmark of Medium Voltage Distribution Network for Investigation of DG Integration. Power Engineering Society General Meeting, IEEE, Montreal, 18-22 June 2006, 6. http://ieeexplore.ieee.org/xpls/icp.jsp?arnumber=1709447

[10] Styczynski, Z.A., Orths, A., Rudion, K., Lebioda, A. and Ruhle, O. (2006) Benchmark for an Electric Distribution System with Dispersed Energy Resources, Transmission and Distribution Conference and Exhibition. 2005/2006 IEEE PES, Dallas, 21-24 May 2006, 314, 320, 21-24. http://ieeexplore.ieee.org/xpls/abs_all.jsp?arnumber=1668510

[11] Papathanassiou, S., Hatziargyriou, N. and Strunz, K. (2005) A Benchmark Low Voltage Microgrid Network, Power Systems with Dispersed Generation: Technologies, Impacts on Development, Operation and Performances. CIGRE Symposium, Athens, 13-16 April 2005, 1-8.

[12] DISCERN Project D1.1. List of Agreed KPIs with Associated Metrics and Refined Smart Grids Functionalities List.

[13] DISCERN Project D6.3. Communication Infrastructure Simulation and Assessment.

[14] Falaghi, H., Haghifam, M.R. and Osoulitabrizi, M.R. (2005) Fault Indicators Effects on Distribution Reliability Indices. Proceedings CIRED Conference, Turin, 6-9 June 2005. http://dx.doi.org/10.1049/cp:20050894

[15] Haakana, J., Lassila, J., Kaipia, T. and Partanen, J. (2010) Comparison of Reliability Indices From the Perspective of Network Automation Devices. IEEE Transactions on Power Delivery, 25, 1547-1555.

http://ieeexplore.ieee.org/xpls/abs_all.jsp?arnumber=5471075 http://dx.doi.org/10.1109/TPWRD.2010.2048131

[16] DISCERN Project D6.4. Technical Evaluation of the DISCERN Solutions Based on Simulations.

[17] DISCERN Project D1.2. Intermediate KPIs Fulfilment Report-KPI Questionnaire. 